\title{
PENGARUH PUPUK NPK PHONSKA TERHADAP PERTUMBUHAN DAN HASIL TUMPANG SARI CABAI (Capsicum annum L.) DAN BAWANG MERAH (Allium cepa L.)
}

\author{
Josina I.B.Hutubessy \\ Program StudiAgroteknologiFakultasPertanianUniversitas Flores \\ Irenehutubessy91@yahoo.co.id
}

\begin{abstract}
Red chili (Capsicum annuum L.) is one of the vegetable commodities that has bright prospects and market demand continues to increase along with the increase in population, but until now the chili has not been able to meet the needs of the community. Efforts to increase production to meet needs that cover quality and quantity can be done by planting intercropping and fertilizing NPK Phonska. This study aims to determine the effect of NPK Phonska fertilizer on the growth and yield of intercropping of optimal chilli and shallot plants. The experimental design used a Randomized Block Design (RBD) with a single factor pattern consisting of 5 NPK Phonska fertilizer treatments, namely BC0 $=0 \mathrm{~kg} \mathrm{ha}^{-1}$ (control), BC1 = $300 \mathrm{~kg} \mathrm{ha}^{-1}, \mathrm{BC} 2=600 \mathrm{~kg} \mathrm{ha}^{-1}, \mathrm{BC} 3=900 \mathrm{~kg} \mathrm{ha}^{-1}, \mathrm{BC} 4=1200 \mathrm{~kg} \mathrm{ha}^{-1}$. Nondestructive data collection is carried out. F test level $5 \%$ to test the effect of treatment, the difference between treatments was based on 5\% BNT Value. The results showed that administration of NPK Phonska fertilizer had a very significant effect on chili plants, namely on growth variables and yields of plant height $26.14 \mathrm{~cm}$, number of leaves of 15.11 strands, leaf area of $11.86 \mathrm{~cm}^{2}$ and plant high onion 33, $34 \mathrm{~cm}$, number of leaves 33.14 strands. The optimum dose of NPK Phonska fertilizer which provides optimal growth and yield of intercropping of chili and shallot plants is $1200 \mathrm{~kg} \mathrm{ha}^{-1}$.
\end{abstract}

\section{Kata kunci : NPK Phonska Fertilizer, Intercropping With Chili and Red Onion}

\section{PENDAHULUAN}

Cabai merah (Capsicum annuum L.) merupakan salah satu komoditas sayuran yang mempunyai prospek cerah dalam upaya meningkatkan taraf hidup petani (Rukmana, 2007). BadanPusatStatistik Indonesia tahun 2015, menunjukanbahwa produktivitas cabai merah di NTB dan Bali yaitu sebesar 8,08 ton $\mathrm{ha}^{-1}$ dan hasil 11,55 ton $\mathrm{ha}^{-1}$, BPS Provinsi NTT tahun 2015 menunjukan bahwa produktivitas cabai merah NTT sebesar 5,87 ton $\mathrm{ha}^{-1}$, yang mana jauh lebih rendah jika dibandingkan dengan Provinsi NTB dan Bali. Berdasarkan data dari Dinas Pertanian Kabupaten Ende, total luas lahan yang dapat ditanami cabai adalah 11,2 ha sedangkan luas lahan yang dapat dipanen hanya 9,5 ha yang mencapai total produksi 66,5 ton dengan produktivitas 7 ton/ha.

Salah satupenyebabsemakinrendahnya produksi cabai adalah makin berkurangnya lahan pertanian yang ada di Kabupaten Ende 
Lahan

lahanpertaniantelahdialihfungsikanuntukaktivita

s lainnya yang lebih bernilai eknomis. Salah satu bentuk untuk mengatasi permasalahan berkurangnya lahan pertanian, maka dapat dilakukan dengan penerapan teknologi pola tanamtumpang sari.

Tumpangsari merupakan teknik penanaman dua jenis tanaman atau lebih pada sebidang lahan yang sama pada waktu yang sama maupun berbeda (Francis et al., 2006). Pada sistem tumpangsari ini melibatkan dua jenis tanaman, maka kehadiran tanaman lain akan terjadi kompotisi baik yang menguntungkan maupun merugikan kelompok tanaman tertentu. Oleh karena itu besar sumbangan yang akan diberikan dalam sistem tanam tumpangsari terhadap perolehan hasil, sangat ditentukan oleh kombinasi tanaman serta pengaturan waktu tanam untuk sedapat mungkin menekan terjadinya kompotisi yang dapat menurunkan hasil panen.Tumpang sari yang umum dilakukan adalah penanaman dalam waktu yang hampir bersamaan untuk dua jenis tanaman budidaya yang sama. Dalam kepustakaan, hal ini dikenal sebagai doublecropping, penanaman yang dilakukan segera setelah tanaman pertama dipanen (seperti jagung dan kedelai atau jagung dan kacang panjang) dikenal sebagai tumpang gilir (relay cropping).

Pelaksanaanpolatanamtumpang sari dapat meningkatkan produksi tanaman bila didukung oleh pemilihan tanaman yang tepat.Hal ini agar tidak terjadi atau meminimalisir terjadinya kompetisi terhadap faktor tumbuh. Karena itu, tanaman cabai ideal untuk ditumpangsarikan dengan tanaman bawang merah. Hal ini terkait dengan waktu tanamannya yang berbeda pada beberapa fase tumbuh. Dengan demikian kompetisi dalam memperoleh faktor tumbuh dapat diminimalisir. Selain pengaturan waktu tanam yang tepat, pemilihan jenis tanaman yang sesuai untuk ditumpangsarikan dengan tanaman cabai besar, penambahan pupuk NPK untuk mendukung pertumbuhan dan perkembangan suatu tanaman yang ditumpangsari juga merupakan salah satu alternatif untuk mendukung pemenuhan kebutuhan tanaman akan untur hara yang cukup.

Pupuk merupakan unsur hara yang ditambahkan ke dalam tanah untuk meningkatkan kesuburan tanah dan tanaman. Jenis pupuk yang ditambahkan ke dalam tanah dapat berupa pupuk organik maupun pupuk anorganik. Pupuk anorganik dapat cepat tersedia bagi tanaman dan dapat menyediakan unsur hara dalam jumlah yang banyak (Hanafiah, 2010). Salah satu pupuk yang sudah sejak lama digunakan petani sebagai penyubur tanah adalah pupuk NPK. Pupuk yang mengandung NPK memberikan pengaruh yang sangat besar terhadap pertumbuhan dan hasil tanaman. Pupuk NPK juga menyumbang sejumlah hara ke dalam tanah yang dapat berfungsi guna menunjang 


\section{Hutubessy : Pupuknpk Phonska, Tumpang Sari Cabai Dan Bawang Merah}

pertumbuhan dan perkembangan tanaman (Djafarudin, 2004). Salah satu jenis pupuk NPK yang dapat digunakan adalah NPK Phonska. Pupuk NPK Phonska merupakan pupuk majemuk yang mengandung $15 \% \mathrm{~N}, 15 \% \mathrm{P}$, 15\% K dan $10 \%$ S (Petro Kimia Gresik, 2012). Dengan kandungan hara makro ini, maka akan membantu meningkatkan pertumbuhan dan produksi tanaman. Namun dalam pengaplikasiannya, harus memperhatikan dosis yang tepat. Hasil penelitian yang telah dilakukan Sumarni dkk (2012) menunjukan bahwa pemberian pupuk NPK $600 \mathrm{~kg}$ ha-1 memberikan pengaruh pada produksi bawang merah tertinggi yaitu 34,94 ton ha-1. Penelitian ini bertujuan untuk mengetahui pengaruh pupuk NPK Phonska terhadap pertumbuhan dan hasil dan mengetahui dosis optimum pupuk NPK Phonska yang memberikan pertumbuhan dan hasil optimal pada sistem tumpang sari tanaman Cabai dan Bawang Merah.

\section{BAHAN DAN METODE}

Penelitiandilaksanakan di desa Woloara kecamatan Kelimutu kabupaten Ende. Waktu penelitian mulai dari bulan Februari sampai Mei 2017.Bahan yang digunakan dalam penelitian ini adalah benih tanaman cabai dan bawang merah serta pupuk NPK Phonska tali rafia. Alat yang digunakan dalam penelitian ini adalah linggis, cangkul, skop, parang, sabit, ember, penggaru, meter, timbangan, mistar, drum plastik, tarpal, ayakan, gembor, gunting, kantung plastik dan alat tulis.

Perlakuan pupuk NPK Phonska, yaitu $\mathrm{BC}_{0}$ $=0 \mathrm{~kg} \mathrm{ha}^{-1}$ (kontrol), $\mathrm{BC}_{1}=300 \mathrm{~kg} \mathrm{ha}^{-1}, \mathrm{BC}_{2}=$ $600 \mathrm{~kg} \mathrm{ha}^{-1}, \mathrm{BC}_{3}=900 \mathrm{~kg} \mathrm{ha}^{-1}, \mathrm{BC}_{4}=1200 \mathrm{~kg}$ $\mathrm{ha}^{-1}$. Pengumpulan data dilakukan secara Non destruktif.

Pengumpulan data dilakukan secara non destruktif pada setiap umur pengamatan (14, 28hari setelah tanam (hst) untuk tanaman cabai dan 14, 21, 28 35, 42 hst untuk tanaman bawang merah ) pada setiap perlakuan utuk komponen pertumbuhan mencakup tinggi tanaman $(\mathrm{cm})$, Luas daun $\left(\mathrm{cm}^{2}\right)$ sedangkan komponen hasil yang meliputi (Jumlah buah total tan ${ }^{-1}$,jumlah buah total $\mathrm{Ha}^{-1}$, berat buah segar total tanan ${ }^{-1}$ (Kg), berat buah segar total $\mathrm{Ha}^{-1}$ (ton) dan berat segar brangkasang (Kg) untuk tanaman cabai dan jumlah umbi tan ${ }^{-1}$, berat umbi segar petak ${ }^{-1}$ (Kg), berat umbi segar $\mathrm{Ha}^{-1}$ (Ton) untuk tanaman bawang merah).

Uji F taraf 5\% untuk menguji pengaaruh perlakuan, perbedaan antar perlakuan didasarkan pada Nilai BNT 5\%. (Gomes 2007).

\section{HASIL DAN PEMBAHASAN}

Secara umum penggunaan pupuk NPK Phonska dengan dosis yang berbeda memberikan pengaruh yang sanggat nyata terhadap komponen pertumbuhan dan hasil tanaman cabai dan tanaman bawang merah pada sistem tanam 
tumpangsari yang mencakup variabel pertumbuhan (Tabel. 1)

Tabel 1 Signifikasi Pengaruh Pemberian Pupuk NPK Phonska Terhadap Seluruh Variabel Pengamatan Tanaman Cabai dan Bawang Merah.

\begin{tabular}{|c|c|c|}
\hline No & Variabel & Signifikasi \\
\hline $\mathbf{I}$ & Tanaman Cabai & \\
\hline 1 & Tinggi tanaman $14,28 \mathrm{hst}$ & $* *$ \\
\hline 2 & Jumlah daun $14,28 \mathrm{hst}$ & $* *$ \\
\hline 3 & Luas daun $14,28 \mathrm{hst}$ & $* *$ \\
\hline 4 & Jumlah buah $\tan ^{-1}$ & $* *$ \\
\hline 5 & Jumlah buah ha h $^{-1}$ & $* *$ \\
\hline 6 & Berat segar buah $\tan ^{-1}$ & $* *$ \\
\hline 7 & Berat segar buan lan & $* *$ \\
\hline 8 & Berat segar buah ha & $* *$ \\
\hline & Berat brangkasan segar & \\
\hline II. & Tanaman Bawang Merah & \\
\hline 1 & Tinggi tanaman $14,21,28,35,42 \mathrm{hst}$ & $* *$ \\
\hline 2 & Jumlah daun $14,21,28,35,42$ hst & $* *$ \\
\hline $\begin{array}{l}2 \\
3\end{array}$ & Jumlah umbi $\tan ^{-1}$ & $* *$ \\
\hline 4 & Berat segar umbi Petak ${ }^{-1}$ & $* *$ \\
\hline 5 & Berat segar umbi ha ${ }^{-1}$ & $* *$ \\
\hline
\end{tabular}

Keterangan: Hst : Hari Setelah Tanam, $* * \quad$ : Sangat Nyata

\section{KOMPONEN PERTUMBUHAN}

Hasil analisis sidik ragam menunjukan bahwa dengan pemberian dosis pupuk NPK Phonska yang berbeda memberikan pengaruh yang sangat nyata terhadap semua variebel pertumbuhan pada setiap umur pengamatan tanaman cabai (Tabel 2) dan tanaman bawang merah (Tabel 3).

Tabel 2 Pengaruh Pemberian Dosis Pupuk NPK Phonska Terhadap Variabel Pertumbuhan Pada Tanaman Cabai. Umur Tanaman Perlakuan Tinggi Tanaman $(\mathrm{cm})$ Jumlah Daun (Helai)Luas Daun $(\mathrm{cm} 2)$

\begin{tabular}{|c|c|c|c|c|c|c|}
\hline $\begin{array}{c}\text { Umur } \\
\text { Tanaman }\end{array}$ & Perlakuan & $\begin{array}{c}\text { Tinggi Tanaman } \\
(\text { (cm) }\end{array}$ & $\begin{array}{r}\text { Jumlah Daun } \\
\text { Helai ) }\end{array}$ & ( & Luas Dau & $\left(\mathrm{cm}^{2}\right)$ \\
\hline \multirow{5}{*}{14 HST } & $\mathrm{BC}_{0}$ & $10.25_{\mathrm{a}}$ & $10.55_{\mathrm{a}}$ & & 1.11 & a \\
\hline & $\mathrm{BC}_{1}$ & $10.97 \mathrm{~b}$ & $11.41_{b}$ & & 1.83 & b \\
\hline & $\mathrm{BC}_{2}$ & $11.24_{\mathrm{c}}$ & $12.28_{\mathrm{c}}$ & & 2.07 & $\mathrm{bc}$ \\
\hline & $\mathrm{BC}_{3}$ & $11.52_{\mathrm{d}}$ & $13.14_{\mathrm{d}}$ & & 2.55 & $\mathrm{~cd}$ \\
\hline & $\mathrm{BC}_{4}$ & $11.79_{\mathrm{e}}$ & $14.00_{\mathrm{e}}$ & & 3.27 & $\mathrm{e}$ \\
\hline \multirow{5}{*}{28 HST } & $\mathrm{BC}_{0}$ & $19.93_{\mathrm{a}}$ & $10.44_{\mathrm{a}}$ & & 8.94 & $\mathrm{a}$ \\
\hline & $\mathrm{BC}_{1}$ & $21.39_{b}$ & $12.53_{\mathrm{b}}$ & & 9.67 & b \\
\hline & $\mathrm{BC}_{2}$ & $22.71_{c}$ & $13.40_{\mathrm{c}}$ & & 10.42 & c \\
\hline & $\mathrm{BC}_{3}$ & $24.25_{\mathrm{d}}$ & $14.25_{\mathrm{d}}$ & & 11.14 & d \\
\hline & $\mathrm{BC}_{4}$ & $26.14_{\mathrm{e}}$ & $15.11_{\mathrm{e}}$ & & 11.86 & $\mathrm{e}$ \\
\hline \multicolumn{2}{|c|}{ BNT } & 0.26 & 0.85 & \multicolumn{3}{|c|}{0.71} \\
\hline
\end{tabular}

Keterangan: Angka-angka yang diikuti oleh huruf yang sama pada kolom yang sama menunjukan pengaruh yang tidak berbeda nyata pada taraf uji BNT $5 \%$. 


\section{Hutubessy : PupukNPK Phonska, tumpang sari cabai dan bawang merah}

Tabel 3 Pengaruh Dosis Pupuk NPK Phonska Terhadap Variabel Pertumbuhan Pada Tanaman Bawang Merah

\begin{tabular}{|c|c|c|c|c|c|c|}
\hline $\begin{array}{c}\text { Tinggi } \\
\text { Tanaman } \\
\text { (cm) }\end{array}$ & Perlakuan & 14 Hst & 21 Hst & 28 Hst & 35 Hst & $42 \mathrm{hst}$ \\
\hline & $\mathrm{BC}_{0}$ & $12.21 \mathrm{a}$ & $13.52 \mathrm{a}$ & $15.77 \mathrm{a}$ & $20.20 \mathrm{a}$ & $22.29 \mathrm{a}$ \\
\hline & $\mathrm{BC}_{1}$ & $13.32 \mathrm{~b}$ & $14.77 \mathrm{~b}$ & $17.49 \mathrm{~b}$ & $23.43 \mathrm{~b}$ & $25.31 \mathrm{~b}$ \\
\hline & $\mathrm{BC}_{2}$ & $14.44 \mathrm{c}$ & $15.81 \mathrm{c}$ & $18.42 \mathrm{c}$ & $25.35 \mathrm{c}$ & $27.28 \mathrm{c}$ \\
\hline & $\mathrm{BC}_{3}$ & $15.38 \mathrm{~d}$ & $17.03 \mathrm{~d}$ & $21.80 \mathrm{~d}$ & $28.05 \mathrm{~d}$ & $30.34 \mathrm{~d}$ \\
\hline & $\mathrm{BC}_{4}$ & $16.43 \mathrm{e}$ & $18.13 \mathrm{e}$ & $25,34 \mathrm{e}$ & $32.42 \mathrm{e}$ & $33.34 \mathrm{e}$ \\
\hline & BNT 5\% & 0.53 & 0.74 & 0.85 & 0.90 & 1.01 \\
\hline \multirow[t]{7}{*}{$\begin{array}{c}\text { Jumlah } \\
\text { Daun }\end{array}$} & Perlakuan & 14 Hst & 21 Hst & $28 \mathrm{HST}$ & 35 Hst & 42 Hst \\
\hline & $\mathrm{BC}_{0}$ & $10.06 \mathrm{a}$ & $14.80 \mathrm{a}$ & $19.80 \mathrm{a}$ & $21.80 \mathrm{a}$ & $19.80 \mathrm{a}$ \\
\hline & $\mathrm{BC}_{1}$ & $11.47 \mathrm{~b}$ & $16.62 \mathrm{~b}$ & $24.62 \mathrm{~b}$ & $25.62 b$ & $24.62 \mathrm{~b}$ \\
\hline & $\mathrm{BC}_{2}$ & $13.83 \mathrm{c}$ & $18.94 \mathrm{c}$ & $26.94 \mathrm{c}$ & $28.94 \mathrm{c}$ & $26.94 \mathrm{c}$ \\
\hline & $\mathrm{BC}_{3}$ & $15.96 \mathrm{~d}$ & $20.34 \mathrm{~d}$ & $29.34 \mathrm{~d}$ & $32.34 \mathrm{~d}$ & $29.34 \mathrm{~d}$ \\
\hline & $\mathrm{BC}_{4}$ & $17.53 \mathrm{e}$ & $23.14 \mathrm{e}$ & $33.14 \mathrm{e}$ & $35.14 \mathrm{e}$ & $33.14 \mathrm{e}$ \\
\hline & BNT 5\% & 0.16 & 0.39 & 0.56 & 0.61 & 0.75 \\
\hline
\end{tabular}

Keterangan: Angka-angka yang diikuti oleh huruf yang sama pada kolom yang sama menunjukan pengaruh yang tidak berbeda nyata pada taraf uji BNT 5\%.

Hasil analisis sidik ragam yang disajikan pada Tabel 1 untuk variabel pengamatan pertumbuhan tanaman cabai menunjukan tinggi tanaman yang paling tinggi didapatkan pada perlakuan $\mathrm{BC} 4$, sedangkan tinggi tanaman yang paling rendah didapatkan pada perlakuan kontrol. Secara keseluruhan pengubahan atau peningkatan dosis pipuk NPK yang diaplikasikan dari BC0 menjadi BC1 pada sistem tanam tumpangsari mampu memberikan pertumbuhan yang pesat terhadap tinggi tanaman cabai sebesar $(6.74 \%)$ dan sebesar $(4.71 \%)$ jika dibandingkan dengan perlakuan $\mathrm{BC} 2$, ketika dosiss NPK ditingkatkan dari $\mathrm{BC} 0$ menjadi $\mathrm{BC} 3$ meningkatkan tinggi tanaman sebesar (5.09\%) dan sebesar (5.69\%) jika dosis pupuk NPK ditingkatkan menjadi BC4. Hal tersebut juga terjadi pada variebael pengamatan jumlah daun maupun luas daun, terkecuali pada variabel pengamatan luas daun pada umur pengamatan 14 hst dimana perlakuan $\mathrm{BC} 1$ dan $\mathrm{BC} 2$ memberikan pengaruh yang tidak berbeda nayata akan tetapi perlakuan penambahan pupuk NPK secara keseluruhan berbeda nyata dengan perlakuan kontrol, dan perlakuan BC4 mampu meningkatkan luas daun sebesar $(9.52 \%)$ jika dibandingkan dengan perlakuan $\mathrm{BC} 3$, dan $\mathrm{BC} 2$ sebesar $(8.77 \%)$ sedangkan BC1 sebesar $(7.85 \%)$ demikian juga dengan BC0 sebesar (12.69\%). Secara keseluruhan makin rendah dosis pupuk 
NPK yang diaplikasikan akan semakin sempit luas daun tanaman Cabai yang di peroleh. Sedangkan untuk variabel pengamatan pertumbuhan tanaman bawang merah yang ditunjukan pada Tabel 3 menunjukan tinggi tanaman dan jumlah daun memberikan pengaruh yang sangat nyata dari perlakuan yang diaplikasikan. Perlakuan dosis pupuk NPK memperlihatkan terbentuk pola yang sama untuk semuah umur pengamatan. Tinggi tanaman yang lebih tinggi umumnya didapatkan pada perlakuan dosis pupuk NPK BC4. Peningkatan tinggi tanaman rata rata sebesar $(9.57 \%)$ terjadi ketika dosis pupuk NPK diubah dari BC4 menjadi BC3, demikian juga dengan perlakuan BC2 dan BC1 maupun BC0. Namun polah yang sama juga terjadi untuk variabel pengamatan jumlah daun tanaman bawang.

Perlakuaan dosis pupuk NPK Phonska $1200 \mathrm{~kg}$ ha-1 (BC4) memberikan pertumbuhan tinggi tanaman, jumlah daun, dan luas daun yang paling tinggi dibandingkan dengan perlakuan lainya. Pupuk NPK phonska merupakan pupuk majemuk, pupuk ini mengandung lebih dari 1 unsur hara sekaligus. Unsur hara yang terkandung di dalam pupuk NPK Phonska adalah $\mathrm{N} 15 \%, \mathrm{P} 15 \%, \mathrm{~K} 15 \%$ dan $\mathrm{S} 10 \%$. Meningkatnya persentase tinggi tanaman menunjukkan bahwa semakin banyak dosis yang diberikan semakin meningkatkan pertumbuhan tanaman cabai dan bawang merah, selain itu NPK Phonska sebagai sumber bahan anorganik mengandung unsur hara yang dapat meningkat pertumbuhan serta produksi tanaman, diantaranya jumlah kandungan unsur $\mathrm{N}, \mathrm{P}$ dan $\mathrm{K}$ juga meningkat. Pada pertumbuhan bagian vegetatif tanaman membutuhkan unsur $\mathrm{N}$ dalam jumlah relatif besar (Novizan, 2007).Unsur N merupakan unsur hara utama bagi pertumbuhan tanaman yang pada umumnya sangat diperlukan untuk pertumbuhan vegetatif tanaman (Sutedjo, 2002). Kandungan hara yang ada di dalam pupuk tersebut merupakan unsur hara makro yang penting bagi tanaman. Keberadaan unsurunsur tersebut dapat meningkatkan pertumbuhan tanaman. Manfaat pupuk NPK Phonska bagi pertumbuhan tanaman adalah mudah diserap tanaman sebab sifatnya yang higroskopis, mengandung berbagai unsur yang dibutuhkan oleh tanaman, sesuai untuk berbagai jenis tanaman, karena kandungannya yang merata dan lengkap, menambah daya tahan tanaman terhadap gangguan hama, penyakit, dan kekeringan, menjadikan tanaman lebih hijau dan segar karena banyak mengandung butir hijau daun, memacu pertumbuhan akar dan sistem perakaran yang baik, menjadikan batang lebih tegak, kuat, dan dapat mengurangi resiko rebah (Naibaho, 2003).Tanaman cabai dan bawang merah tanpa pemberian pupuk NPK phonska (BC0) memberikan penampilan variabel pertumbuhan yang paling rendah dibanding perlakuan lainya. Hal ini disebabkan karena 


\section{Hutubessy : PupukNPK Phonska, tumpang sari cabai dan bawang merah}

kurangnya pasokan unsur hara untuk dapat membentuk organ vegetatifnya.

\section{KOMPONEN HASIL}

Hasil analisis sidik ragam menunjukan bahwa pemberian dosis pupuk NPK Phonska yang berbeda memberikan pengaruh yang sangat nyata terhadap seluruh variabel hasil tanaman cabai (Tabel 4) dan tanaman bawang merah (Tabel 5).

Tabel 4 Pengaruh Pemberian Dosis Pupuk NPK Phonska Terhadap Seluruh Variabel Hasil Tanaman cabai.

\begin{tabular}{|c|c|c|c|c|c|}
\hline Perlakuan & $\begin{array}{c}\text { Jumlah } \\
\text { Buah Total } \\
\text { Tan }^{-1} \\
\end{array}$ & $\begin{array}{c}\text { Jumlah Buah } \\
\text { Total } \mathrm{Ha}^{-1} \\
\text { (ratus ribu) }\end{array}$ & $\begin{array}{c}\text { Berat Buah } \\
\text { Segar Total Tan } \\
{ }^{1}(\mathrm{Kg}) \\
\end{array}$ & $\begin{array}{c}\text { Berat Buah } \\
\text { Segar Total Ha } \\
{ }^{1} \text { (ton) }\end{array}$ & $\begin{array}{c}\text { Berat Segar } \\
\text { Brangkasan } \\
(\mathbf{k g}) \\
\end{array}$ \\
\hline $\mathrm{BC}_{0}$ & $23.21 \mathrm{a}_{\mathrm{a}}$ & $6,18 a_{a}$ & $0.23 \mathrm{a}_{\mathrm{e}}$ & $6.13 \mathrm{a}_{\mathrm{e}}$ & $0.15 \mathrm{a}_{\mathrm{e}}$ \\
\hline $\mathrm{BC}_{1}$ & $24.39 b_{a}$ & $6.50 b_{a}$ & $0.27 \mathrm{a}_{\mathrm{d}}$ & $7.19 b_{d}$ & $0.18 \mathrm{a}_{\mathrm{d}}$ \\
\hline $\mathrm{BC}_{2}$ & $25.75 c_{a}$ & $6.87 \mathrm{~cd}_{\mathrm{a}}$ & $0.30 \mathrm{a}_{\mathrm{c}}$ & $7.99 c_{c}$ & $0.22 \mathrm{a}_{\mathrm{c}}$ \\
\hline $\mathrm{BC}_{3}$ & $26.47 \mathrm{~d}_{\mathrm{a}}$ & $7.05 \mathrm{~d}_{\mathrm{a}}$ & $0.34 \mathrm{a}_{\mathrm{b}}$ & $9.06 \mathrm{~d}_{\mathrm{b}}$ & $0.26 \mathrm{a}_{\mathrm{b}}$ \\
\hline $\begin{array}{c}\mathrm{BC}_{4} \\
\text { RNT 5\% }\end{array}$ & $28.51 \mathrm{e}_{\mathrm{a}}$ & $7.71 \mathrm{e}_{\mathrm{a}}$ & $0.37 \mathrm{a}_{\mathrm{a}}$ & $9.86 \mathrm{e}_{\mathrm{a}}$ & $0.31 \mathrm{a}_{\mathrm{a}}$ \\
\hline
\end{tabular}

Keterangan:Angka-angka yang diikuti oleh huruf yang sama pada kolom yang sama menunjukkan pengaruh yang tidak berbeda nyata pada taraf uji BNT $5 \%$.

Tabel 5 Pengaruh Pupuk NPK Phonska Terhadap Seluruh Variabel Hasil Tanaman Bawang Merah.

\begin{tabular}{cccc}
\hline Perlakuan & Jumlah Umbi Tan $^{-\mathbf{1}}$ & $\begin{array}{c}\text { Berat Umbi Segar }^{\text {Petak }} \mathbf{- 1}(\mathbf{K g}) \\
\mathrm{BC}_{0}\end{array}$ & $\begin{array}{c}\text { Berat Umbi Segar } \\
\mathbf{H a}^{-\mathbf{1}} \text { (ton) }\end{array}$ \\
$\mathrm{BC}_{1}$ & $200,34 \mathrm{a} \mathrm{e}$ & $1,22 \mathrm{a} \mathrm{e}$ & $1.36 \mathrm{a} \mathrm{e}$ \\
$\mathrm{BC}_{2}$ & $246.54 \mathrm{~b} \mathrm{~d}$ & $1,39 \mathrm{~b} \mathrm{~d}$ & $1.54 \mathrm{~b} \mathrm{~d}$ \\
$\mathrm{BC}_{3}$ & $321.81 \mathrm{c} \mathrm{c} \mathrm{b}$ & $1,56 \mathrm{c} \mathrm{c}$ & $1.73 \mathrm{c} \mathrm{c}$ \\
$\mathrm{BC}_{4}$ & $354.68 \mathrm{e} \mathrm{a}$ & $1,72 \mathrm{~d} \mathrm{~b}$ & $1.91 \mathrm{~d} \mathrm{~b}$ \\
\hline BNT 5\% & $\mathbf{2 1 . 2 4}$ & $1,95 \mathrm{e} \mathrm{a}$ & $2.16 \mathrm{e} \mathrm{a}$ \\
\hline
\end{tabular}

Keterangan : Angka-angka yang diikuti oleh huruf yang sama pada kolom yang sama menunjukkan pengaruh yang tidak berbeda nyata pada taraf uji BNT 5\%.

Tabel 4 menunjukan rerata jumlah buah total pertanaman, jumlah buah total perhektar, dan berat segar buah total perhektar yang paling tinggi didapatkan pata tanaman cabai besar yang di tanam dengan menggunakan dosis aplikasi pupuk NPK BC4 dan yang terendah didapatkan pada perlakuan $\mathrm{BC} 0$, sedangkan perubahan dosis pupuk NPK dari $\mathrm{BC} 4$ menjadi $\mathrm{BC} 3$ maupun $\mathrm{BC} 2$ dan juga $\mathrm{BC} 1$ menyebapkan peningkatang jumlah buahrata-rata pertanaman sebesar 
(4,99\%), jumlah buah perhektar sebesar $(5,34 \%)$ dan berat buah segar perhektar sebesar $(11,16 \%)$. Sedangkan untuk komponen pengamatan berat buah total pertanaman dan berat berangkasan yang ditunjukan pada Tabel 4 menunjukan hasil yang tidak signifikan ataupun tidak berbeda nyata dari semua perlakuan baik perlakuan kontrol maupun perlakuan dosis pupuk NPK yang paling tinggi yaitu BC4. Namun hasil rerata yang diperoleh dari tanaman bawang merah yang disajikan pada Tabel 5 menunjukan pola yang sama untuk semua variabel pengamatan hasil diantaranya perlakuan kontrol menunjukkan hasil ysng lebih rendah untuk semua variabel pengamatan. secara umum, pengubahan perlakuan dari dosis pupuk NPK dari $\mathrm{BC} 0$ menjadi $\mathrm{BC} 1, \mathrm{BC} 2, \mathrm{BC} 3$ maupun $\mathrm{BC} 4$ berdampak terhadap peningkatan jumlah umbi, berat umbi segar perpetak dan berat umbi segar perhektar yang dihasilkan rata-rata sebesar $(13,22 \%)$ untuk variabel pengamatan jumlah umbi, sedangkan untuk variabel pengamatan berat umbi segar perpetak sebesar $(15,58 \%)$ dan berat umbi segar perhektar sebesar $(10,91 \%)$.

Peningkatan yang terjadi pada variabel hasil tanaman cabai dan bawang merah disebabkan karena semakin banyak dosis pupuk NPK Phonska yang diaplikasikan maka akan semakin banyak unsur hara yang tersedia bagi tanaman. Unsur hara yang tersedia dengan diberinya pupuk NPK phonska adalah N sebanyak 15\%, P $15 \%$, K $15 \%$ dan S $10 \%$.
Unsur hara yang tersedia tersebut, diserap tanaman untuk mendukung proses pertumbuhannya yang pada akhirnya dapat memberikan peningkatan hasil yang optimal. Peningkatanini terjadi karena dengan peningkatan dosis pupuk NPK phonska menyebabkan hasil tanaman cabai dan bawang merah semakin tinggi.

Pemberian dosis pupuk NPK phonska sebanyak $1200 \mathrm{~kg} \mathrm{ha}^{-1}$ (BC4) memberikan hasil tanaman cabai dan bawang merah yang paling tinggi. Hal ini disebabkan karena unsur hara dalam NPK Phonska dapat meningkatkan pertumbuhan tanaman dan hasil tanaman. Hasil tanaman meningkat dengan pemberian pupuk NPK phonska terkait dengan hal berikut yaitu: pupuk ini mudah diserap tanaman sebab sifatnya yang higroskopis, mengandung berbagai unsur yang dibutuhkan tanaman,meningkatkan produksi dan kualitas panen, memacu pembentukan bunga, mempercepat panen memperbesar ukuran buah, umbi, dan biji-bijian dan meningkatkan ketahanan hasil selama pengangkutan dan penyimpanan (Hardjowigeno, 2007). Tanaman akan tumbuh dengan baik apabila segala elemen yang dibutuhkan tersedia dalam jumlah yang cukup dan dalam bentuk yang siap diserap oleh tanaman (Purwaningsih, 2012).

Tanaman cabai dan bawang merah tanpa pemberian pupuk NPK Phonska (BC0) memberikan penampilan variabel hasil yang 


\section{Hutubessy : PupukNPK Phonska, tumpang sari cabai dan bawang merah}

paling rendah dibanding perlakuan lainnya. Hal ini disebabkan karena kurangnya pasokan unsur hara di dalam tanah sehingga tidak dapat meningkatkan pertumbuhan dan hasil tanaman yang optimal. Tanaman yang kekurangan unsur hara makro, terutama $\mathrm{N}, \mathrm{P}, \mathrm{K}$ dan $\mathrm{S}$ akan terhambat pertumbuhannya, baik pertumbuhan organ vegetatif maupun generatif. Hal ini berdampak pada makin rendahnya produksi tanaman tersebut.

\section{SIMPULAN}

1. Hasil penelitian menunjukkan bahwa pemberian pupuk NPK Phonska memberikan pengaruh yang sangat nyata pada tanaman cabai yaitu terhadap variabel pertumbuhan dan hasil tanaman tinggi tanaman 26,14 cm, jumlah daun 15,11 helai, luas daun $11,86 \mathrm{~cm}^{2}$ dan bawang merah tinggi tanaman 33,34 cm, jumlah daun 33,14 helai.

2. Dosis optimum pupuk NPK Phonska yang memberikan pertumbuhan dan hasil tumpang sari tanaman cabai dan bawang merah yang optimal adalah $1200 \mathrm{~kg} \mathrm{ha}^{-1}$.

\section{UCAPAN TERIMA KASIH}

Pada kesempatan ini penulis ingin mengucapkan terima kasih kepada semua pihak yang telah membantu dengan caranya masing-masing dalam melengkapi tulisan ini.

\section{DAFTAR PUSTAKA}

Badan Pusat Statistik Kabupaten Ende. 2010. Produksi dan Produtivitas Cabai.

Francis, C., A. Jons., K. Wittler and S. Goodman. 2006. Strip Cropping Corn and Grain Legumes: A Review. Amer. J. I of Alternative Agric : $1-8$.

Gomez, K.A., Gomez, A.A. 2007. Prosedur Statistik Untuk Penelitian Pertanian. Jakarta. Universitas Indonesia Press.

Hanafiah. 2010. Dasar-Dasar Ilmu Tanah. Rineka Cipta. Jakarta

Novizan.2007. Petunjuk Pemupukan Yang Efektif.Agromedia Pustaka. Jakarta

SarwonoHarjdowigeno.2007.PerananBahanOr ganikTanah.http://isroi.Word pres.com/2009/01/29/peranan-bahanorganik -tanah. Disidir tanggal 06 Juni 2017.

Sumarni.,Rosliani.,Basuki. 2012. Respon Pertumbuhan, Hasil Umbi dan Serapan Unsur Hara NPK Tanaman Bawang Merah Terhadap Berbagai Dosis Pemupukkan NPK Pada Tanah Alluvial. J. Horti. Vol. 22 (4): 366-375

Rukmana Rahmat 2007. Bertanam Cabai

merah. Kanisius. Yogyakarta. 